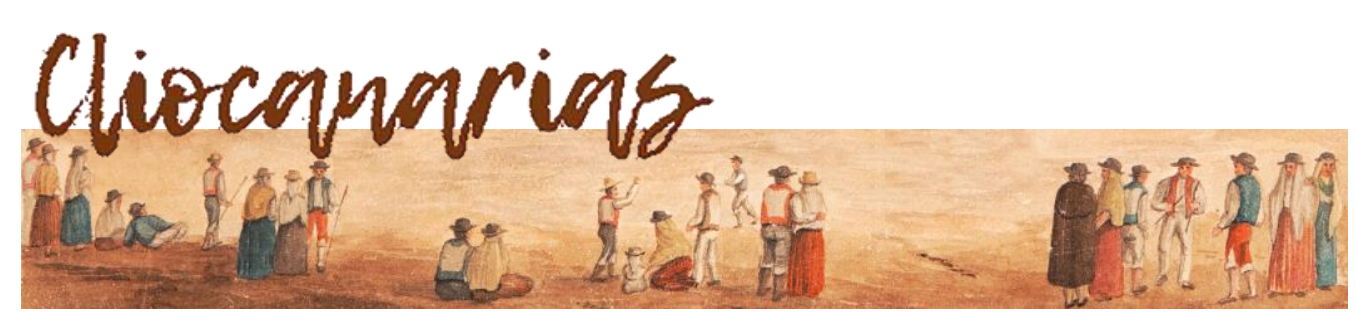

ISSN 2695-4494

https://doi.org/10.53335/cliocanarias.2021.3.06

\title{
ESPAÑOLES, MULATOS Y FILIPINOS EN LA REAL UNIVERSIDAD DE MÉ- XICO. DEBATES Y DISPUTAS POR EL ACCESO A LAS AULAS EN EL SI- GLO XVII
}

SPANISH, MULATTOS AND FILIPINOS AT THE REAL UNIVERSIDAD DE MÉXICO. DEBATES AND DISPUTES OVER ACCESS TO CLASSROOMS IN THE 17TH CENTURY

\author{
Rodolfo AGUIRRE SALVADOR*
}

REsumen: El cambio social en Nueva España se reflejó también en los estudiantes de la Real Universidad de México. Aunque esta se planeó originalmente para los españoles, fundamentalmente, en el siglo XVII otros grupos se hicieron presentes. Mulatos, indios y filipinos demandaron estudios mayores y grados, en la búsqueda de mejorar sus condiciones de vida y el ascenso social de sus familias. Esta aspiración fue rechazada por sectores de españoles intolerantes, causando rechazos de estudiantes y distintas controversias que los dirigentes de la universidad debieron resolver.

PAlabras ClaVE: Real Universidad de México, estudiantes, oríge nes sociales, limpieza de sangre, constituciones.

ABSTRACT: The social change in New Spain was also reflected in the students of the Royal University of Mexico. Although this was originally planned for the Spanish, mainly, in the seventeenth century other groups were present. Mulattoes, Indians and Filipinos demanded major studies and degrees, in the search to improve their living conditions and the social advancement of their families. This aspiration was rejected by intolerant sectors of Spaniards, causing rejections from students and various controversies that the university leaders had to resolve.

KEYWORDS: Royal University of Mexico, students, social origins, blood cleansing, constitutions

\footnotetext{
* Profesor de la Universidad Nacional Autónoma de México (UNAM). C. e.: aguirre_rodolfo@hotmail.com
} 


\section{Introducción}

En el año de 1674 un joven alumno que no pertenecía al grupo sociorracial de los españoles de Nueva España fue objeto de rechazo por otros estudiantes, e incluso un catedrático de la facultad de Medicina de la Real Universidad de la ciudad de México. Esta acción pudo ser un suceso más de la población estudiantil, como muchos otros presenciados en la rutina de los cursos. Sin embargo, también fue un claro indicio del proceso de transformación social que se había operado en la universidad colonial. Casi veinte años después, en 1696, por órdenes del virrey interino, el obispo de Michoacán Juan de Ortega y Montañés, un rector de la universidad formuló un edicto para hacer cumplir la constitución 246 de los estatutos que regian a esa corporación. Esa norma pretendia regular los origenes sociales de los alumnos que cursaban y obtenian los grados universitarios.

Estos eventos presenciados en las aulas universitarias fueron reflejo del proceso de mutación social de la sociedad novohispana de la segunda mitad del siglo XVII. Grupos indígenas, mestizos y mulatos inconformes con el bajo rango social que se les asignaba se dispusieron a acceder a espacios y corporaciones de españoles, intentando un ascenso social y una mejora de sus condiciones de vida en la sociedad ${ }^{1}$.

En las siguientes páginas se estudia la aplicación de la constitución 246 de los estatutos universitarios de 1645 , si bien publicados hasta 1668 . Esta decisión de las autoridades universitarias fue inducida por el interés de estudiantes no españoles de cursar las cátedras y obtener los títulos universitarios. A lo anterior se sumó el ambiente de miedo provocado por el gran tumulto de la ciudad de México en 1692. En el interior de la universidad también hubo descontento en los estudiantes debido a que perdieron prerrogativas en la dirección de dicha institución en favor de la elite académica, conformada por los catedráticos y los doctores. No obstante, los intentos por practicar la constitución 246, la real universidad se volvió más flexible, pues debió afrontar cada vez más la solicitud de estudios y grados de grupos sociales que décadas atrás dificilmente se daba.

\section{Tentativas iniciales para cumplir la constitución 246}

Los cambios sociales que se presenciaron en Nueva España durante el siglo XVII tuvieron consecuencias en corporaciones que, como la universidad, patrocinaban una sociedad gobernada solamente por república de los españoles. En esta aspiración los estudios universitarios no estaban pensados para los indios ni para los nuevos grupos mestizos, por más que los concilios aceptaran

\footnotetext{
${ }^{1}$ LIRA, Andrés y Luis MURO: "El siglo de la integración", en: Historia General de México. Versión 2000, México, El Colegio de México, 2000. También, ALBERRO, Solange: Inquisición y Sociedad en México. 1571-1700, México, Fondo de Cultura Económica, 1988, capítulo "XXX. Negros y mulatos: la integración dolorosa".
} 
dar el sacerdocio a sujetos distinguidos de ese origen ${ }^{2}$. En el tercer concilio mexicano de 1585, y después, en 1588 Felipe II, se dejaba una posibilidad para indios y mestizos bien preparados, de nacimiento legítimo y vida virtuosa ${ }^{3}$.

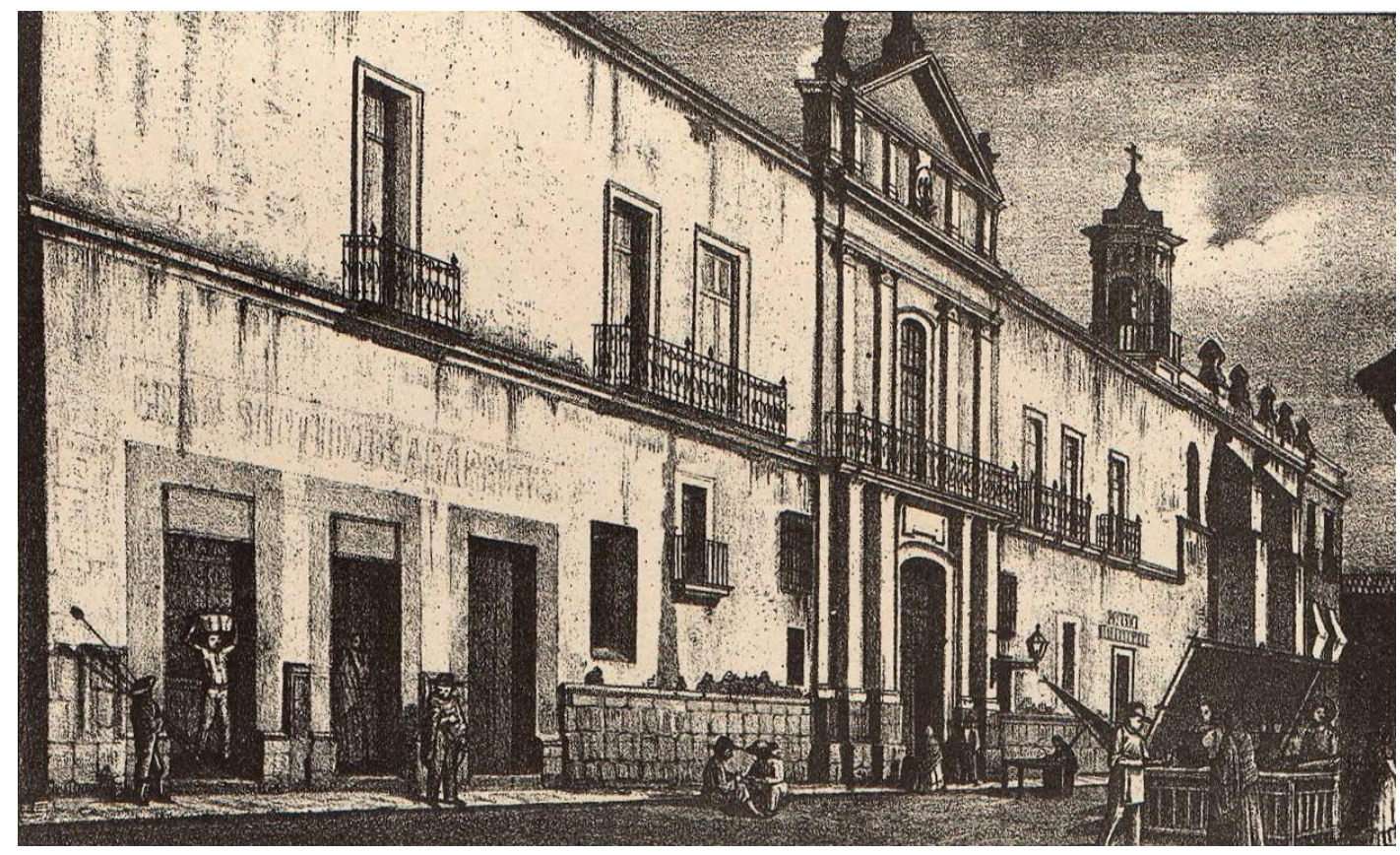

Fachada principal de la Real Universidad de México, en la plaza del Volador. La vida estudiantil transcurría en el corazón de la capital novohispana. Tomada, bajo licencia Creative Commons, de RIVERA CAMBAS, Manuel: México pintoresco, artístico y monumental, en: [<https://cd.dgb.uanl.mx/handle/201504211/12953>].

Aunque la real cédula fundacional de la universidad, en 1551, decretó también el acceso de los indios, como vasallos libres del rey que eran, la catástrofe poblacional indigena y la nueva politica tributaria de Felipe II en la segunda mitad del siglo XVI, que perjudicó notablemente el poder de la nobles indígenas, obstaculizó en los hechos que los nativos pudieran aspirar por entonces a los estudios mayores. La nobleza indigena que sobrevivió a las guerras de conquista estuvo más preocupada por conservar algunos privilegios ${ }^{4}$.

Las condiciones sociales y politicas en que se desenvolvió la sociedad novohispana se modificaron paulatinamente en el siglo XVII. En la Real Univer-

\footnotetext{
2 MENEGUS, Margarita: «Dos proyectos de educación superior en la Nueva España en el siglo XVI. La exclusión de los indígenas de la Universidad", en VV. AA., Historia de la Universidad colonial (avances de investigación), México, CESU-UNAM, 1987, pp. 83-89.

${ }^{3}$ MARTÍNEZ, Pilar, Elisa Itzel GARCÍA, y Marcela Rocío GARCÍA: III concilio y Directorio, libro 1, título IV "De la vida, fama y costumbres de los que se han de ordenar", parágrafo III: Los indios y los mestizos no sean admitidos a los sagrados órdenes sino con la mayor y más cuidadosa elección, en: MARTÍNEZ, Pilar (coord.): Concilios provinciales mexicanos. Época colonial, México, Instituto de Investigaciones Históricas, 2004. Disco compacto. La cédula de 1588 en: Recopilación de leyes de los reynos de las Indias. 1681. Tomo primero, México, Escuela Libre de Derecho-Miguel Ángel Porrúa, 1987, edición facsimilar, f. ${ }^{\circ}$ 32r.

${ }^{4}$ GIBSON, Charles: Los aztecas bajo el dominio español. 1521-1821. México, Siglo XXI, 1989, pp. 138-223.
} 
sidad la población estudiantil también acusó el cambio social, pues los estudiantes comenzaron a proceder de una más amplia base social, como lo muestra la presencia de un joven mulato libre, Pedro Ciprés, en los cursos de la facultad de Medicina durante la década de 1630. La situación provocó la protesta de un grupo de estudiantes españoles, que pidieron incluso su expulsión al virrey marqués de Cerralvo. No obstante, este alto ministro del rey concluyó que, puesto que no existía un estatuto universitario que prohibiera a los mulatos cursar en la universidad, no podía acceder a la exclusión de Ciprés ${ }^{5}$. Sabemos que otro joven mulato estudió Cánones en $1650^{6}$. Si bien aún conocemos pocos casos de estudiantes universitarios no españoles en la primera mitad del seiscientos, son suficientes para indicar tendencias de movilidad social, a través de las letras, en grupos sociorraciales, de bajo rango, que intentaban conquistar una mejor situación. Estas tendencias incomodaban a la elite académica y ocasionaron fricciones en la Real Universidad, tensiones que ya no fueron solo académicas sino también sociales, dada la importancia que en la época tenía la distinción social de los letrados, considerados miembros de la nobleza letrada. Las reacciones en las aulas universitarias ante la tentativa, cada vez más clara, de grupos mestizos e indigenas por introducirse en los cursos y grados, fueron al principio de indiferencia, después de reclamo, incluso eventualmente se convirtió en un franco rechazo.

Antes de las constituciones universitarias de 1645, que permanecieron hasta el fin de la era novohispana, lo que más se aproximó a una regulación del origen social de los estudiantes fue la obligación de los licenciados y de los doctores, la elite académica, de presentar a individuos que testificaran sobre su vida pública y sus costumbres, ante el secretario de la universidad 7 . Esta disposición estuvo vigente hasta la década de 1660, cuando se añadió la obligación de comprobar su limpieza de sangre ${ }^{8}$. Mas con respecto al control de los simples estudiantes no hallamos algo parecido por entonces, como ya el virrey Cerralvo lo habia expresado.

En la década de 1640 el visitador de la universidad, Juan de Palafox y Mendoza elaboró nuevas constituciones de una manera minuciosa, a tal grado que las mismas habrian de perdurar hasta el fin del régimen colonial. Una de estas normas, la 246, estipuló los requisitos sociales de los estudiantes y graduados, y reflejó la aprensión de la elite letrada española por evitar individuos provenientes de otros grupos sociorraciales. La citada constitución ordenó que:

\footnotetext{
5 GONZALBO, Pilar: "¿Qué hacemos con Pedro Ciprés? Aproximaciones a una metodología de la vida cotidiana", en Historia Mexicana, México, El Colegio de México, n. ${ }^{\circ}$ 68, 2018, pp. 471 507.

${ }^{6}$ ALBERRO, Solange: Inquisición y sociedad..., op. cit, pp. 470-471. Se trata de Gaspar Rivero de Vasconcelos.

${ }^{7}$ Es muy probable que tal costumbre se haya originado a raíz del concilio de Trento, que pedía tal tipo de información a los futuros clérigos. Véase sobre todo los concilios de la sesión XXIII "El sacramento del orden", sobre todo el capítulo V: "Qué circunstancias deban tener los que se quieren ordenar" y capitulo VII: "El examen de los ordenandos".

8 Archivo General de la Nación de México (en adelante: AGN). Universidad, vol. 263, grados mayores de Cánones, 1662-1699, f. ${ }^{\circ} 42$.
} 
...cualquiera que hubiere sido penitenciado por el Santo Oficio, o sus padres o abuelos, o tuviere alguna nota de infamia, no sea admitido a grado alguno de esta universidad, ni tampoco los negros ni mulatos, ni los que comúnmente se llaman chinos morenos, ni cualquiera género de esclavo o que lo haya sido: porque no solo no han de ser admitidos a grado, pero ni a la matrícula; y se declara que los indios, como vasallos de su majestad, pueden y deben ser admitidos a matrícula y grados 9 .

Estas lineas contienen las preocupaciones de los dirigentes de la universidad de mediados del siglo XVII. De inicio, la exclusión de los sentenciados por el tribunal del Santo Oficio y sus descendientes se reflejó aquellos años cuando diversos autos de fe dejaron un recuerdo profundo en Nueva España ${ }^{10}$. No obstante, hasta hoy no hemos hallado ningún caso en la universidad de estudiante o graduado denunciado ante el tribunal del Santo Oficio, por lo cual esta prohibición careció de relevancia. En cambio, la frase: ...o tuviere alguna nota de infamia... se prestó a diversas definiciones que podian emplearse contra adversarios o para excluir incluso a jóvenes "españoles" de piel oscura. En el siglo XVIII hubo muchos casos de estudiantes de padres desconocidos, hijos naturales, o bien adoptados en otras familias, que tuvieron que enfrentar esa frase de la constitución $246^{11}$.

La tercera supresión de la 246 se refería a los negros, los mulatos y los chinos morenos; es decir, a asiáticos no cristianos, así como a los esclavos. Esta exclusión fue aplicada formalmente: si un alumno era considerado negro o mulato, era expulsado de la universidad ${ }^{12}$. Esto no significa que ningún mulato consiguiera graduarse, pues hubo quienes pudieron acreditarse con documentos como "españoles" y siguieron adelante en su carrera ${ }^{13}$.

La constitución 246 ordenó también la admisión de los indios. Si bien por entonces aún no había una presencia notoria de ellos, fue importante que el visitador Juan de Palafox reafirmara lo ya señalado en la cédula fundacional de la universidad, pues además concordaba con quienes defendian mejores oportunidades para los indios ${ }^{14}$.

La constitución aludida fue, entonces, una respuesta a las preocupaciones de la elite universitaria. No obstante, al finalizar el siglo XVII fue insuficiente ante una sociedad cambiante cuyo devenir nadie podia predecir. Una sola norma no podía comprender a un abanico social en expansión y, puesto que

\footnotetext{
9 GONZÁLEZ GONZÁLEZ, Enrique, y Víctor GUTIÉRREZ RODRÍGUEZ (eds.): Juan de Palafox y Mendoza. Constituciones para la Real Universidad de México (1645), México, Universidad Nacional Autónoma de México, 2014, p. 178.

10 ALBERRO, Solange: Inquisición y sociedad..., op. cit, pp. 533-585.

${ }^{11}$ AGUIRRE SALVADOR, Rodolfo: «Mismas aulas, diferentes destinos. Los estudios universitarios como factor de ascenso en las carreras públicas», en: Historia Mexicana, México, El Colegio de México, n. ${ }^{\circ}$ 260, abril-junio de 2016, pp. 1709-1749.

12 AGUIRRE SALVADOR, Rodolfo: El mérito y la estrategia. Clérigos, médicos y juristas en Nueva España, México, CESU/Plaza y Valdés, 2003.

13 AGN, Universidad, vol. 129, fols. 212-215v.

14 PALAFOX Y MENDOZA, Juan de: Manual de estados y profesiones. De la naturaleza del indio, México, UNAM/Miguel Ángel Porrúa, 1986.
} 
ya no hubo nuevos estatutos, los dirigentes de la universidad debieron ensayar distintas interpretaciones sobre cuál debía ser la calidad social de los estudiantes, especialmente cuando estos presentaban situaciones no comprendidas en la 246, tanto por aspectos raciales (castizos, mestizos), sociales (defectos de nacimiento, hijos de padres desconocidos, expuestos o hijos naturales), por su origen geográfico (asiáticos). A todo ello hay que agregar la postura de catedráticos menos tolerantes a la presencia de indios en los cursos.

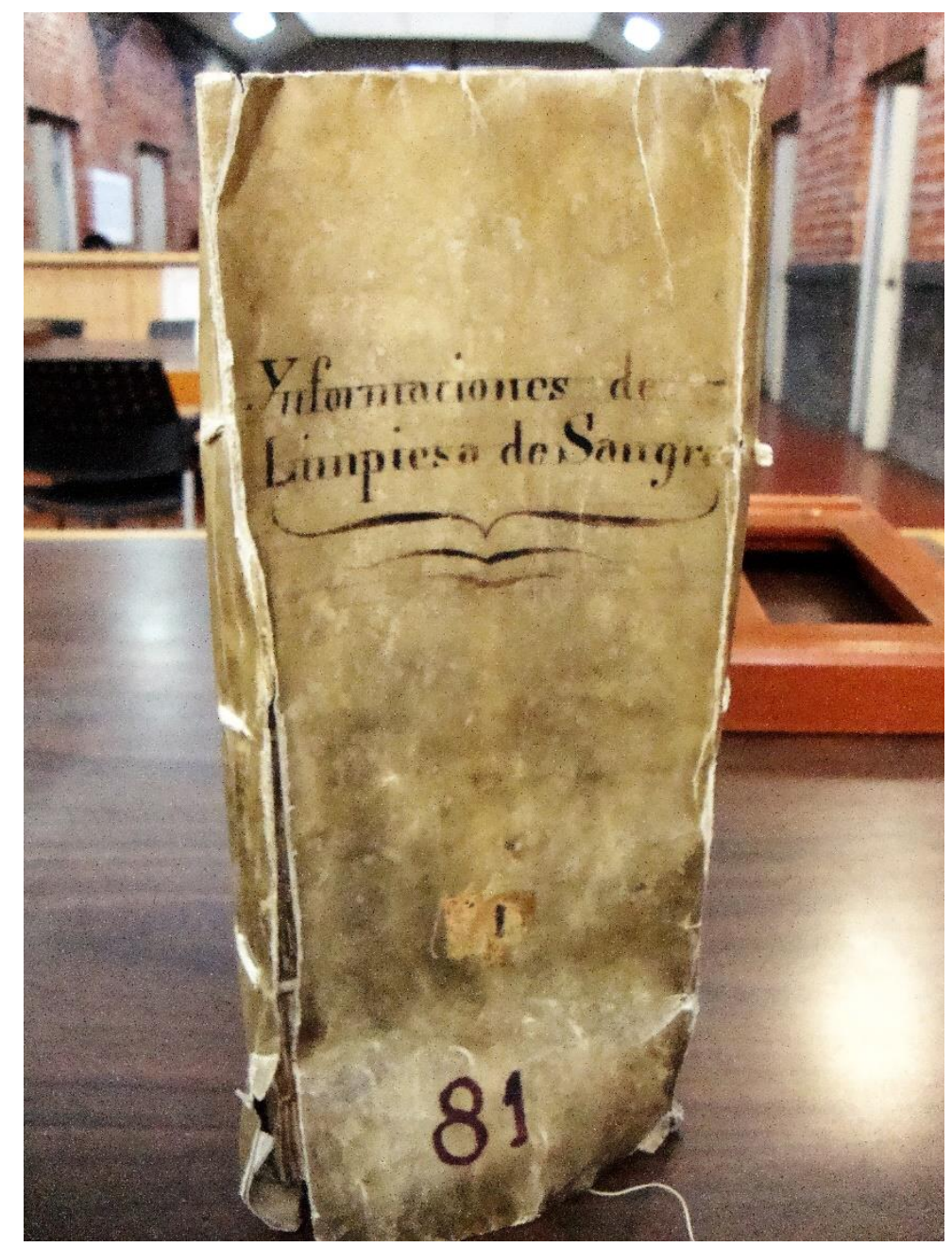

Imagen: Volumen 81 del ramo Universidad, en donde se concentraron diversos expedientes de alumnos con origenes familiares poco deseados por la elite universitaria. Fotografia de Rodolfo Aguirre Salvador. (Autorización del Archivo General de la Nación, México, para la divulgación académica sin fines de lucro).

De esa forma, entre la creación de las constituciones palafoxianas en 1645, y su puesta en práctica en 1668, el arribo de alumnos no españoles parece aumentar en la Real Universidad, especialmente en los cursos de Artes y de Medicina. Hasta entonces no hallamos registros en el archivo universitario que reflejen indagaciones sobre el origen social de los cursantes, aunque sí de los licenciados y de los doctores. Desde el siglo XVI se pidió a estos graduados mayores información de vida y costumbres. A partir de la década de 1630 
aparece en sus expedientes la negación de ser penitenciados por la Inquisición ${ }^{15}$. Años después, las referencias de los graduados mayores sobre su calidad social comprendieron nuevos conceptos: rechazaban ser descendientes de moros, judíos o de recién convertidos a la fe católica, jurando ser hijos de matrimonio legítimo y, además, agregaban su condición de nobleza ${ }^{16}$. Es muy posible que en la década de 1660, al incursionar varios hijos de hidalgos y caballeros de órdenes, se hubiera convertido en costumbre en un sector de los graduados mayores declarar su nobleza, más que su limpieza. En 1683 se citaba ya en las diligencias de graduación a la constitución 246 o "de las personas prohibidas", como se le llamó en la práctica ${ }^{17}$. Así, desde el siglo XVI se prestó atención en el origen de la elite académica de la universidad, pero no en el estudiantado o los bachilleres, por lo menos hasta la séptima década del siglo siguiente.

Pocos años después de la publicación de las constituciones de Palafox hubo ya un incidente en que se solicitó el cumplimiento de la 246. En 1674 el catedrático de Cirugía y Anatomía, Juan de Brizuela, expulsó de su clase a un joven filipino, Manuel de Santa Fe, al considerarlo chino moreno. Este pidió en consecuencia al rector que no se le imposibilitara cursar, pues no era de los que ...comúnmente se llaman chinos morenos ni he sido ni lo han sido mis padres esclavos, pues antes son indios japones blancos, como es manifiesto $y$ notorio y se percibe por la vista de ojos; de que a mayor abundamiento, en caso necesario, ofrezco dar plena información diciendo como somos indios japones libres, vasallos de su majestad...18.

Al respecto, desde el siglo XVI Felipe II había definido a sus vasallos asiáticos como indios ${ }^{19}$. El rector aceptó la defensa de Santa Fe, pues la constitución 246 no detallaba el origen geográfico de los indios y, en consecuencia, ordenó al secretario de la universidad recibir al alumno información sobre su calidad social. El filipino presentó como primer testigo al padre jesuita Agustín Franco, quien expresó que conocía a Pablo de Santa Fe, padre del bachiller, quien también era de origen filipino y no había sido esclavo ni era chino moreno. Un segundo testigo añadió a todo lo anterior que la madre de Santa Fe era Francisca Gutiérrez, natural de la ciudad de México. El estudiante agraviado exhibió también una certificación del colegio jesuita de la capital novohispana que reafirmó todo lo anterior y en el que se especificaba que su padre no era negro, mulato ni indio.

El secretario de la universidad certificó también que Santa Fe ya se había graduado de bachiller en Filosofia pocos dias antes. Ante todo esto, el rector

\footnotetext{
15 AGN, Universidad, vol. 284, grados mayores de Medicina, 1567-1647, f. ${ }^{\circ} 491$.

16 AGN, Universidad, vol. 263, grados mayores de Cánones, 1662-1699.

17 AGN, Universidad, vol. 277, grados mayores de Leyes, 1570-1689, f. ${ }^{\circ}$ 541v.

18 AGN, Universidad, vol. 69, año de 1674, expdte. 2, f. ${ }^{\circ}$ 1: "Autos hechos sobre la pretensión de matricularse en la facultad de Medicina el bachiller Manuel de Santa Fe, entre partes, y de la otra el doctor Juan de Brizuela, catedrático de Cirugía y Anatomía en esta Real Universidad. Juez: el señor doctor don García de León Castillo, rector".

19 Recopilación de leyes, op. cit., tomo segundo, libro VI, título VII, ley XV: "Que los indios principales de Filipinas sean bien tratados y se les encargue el gobierno que solian tener en los otros".
} 
García de León Castillo, quien además era juez ordinario del Santo Oficio, expresó que el estudiante no era:

[...] de los comprendidos en la constitución doscientas cuarenta y seis; y mandaba y mandó se le admita la matrícula para cursar la facultad de Medicina y ningún catedrático de los de dicha facultad se lo impida, pena de veinte pesos aplicados al arca de la Real Universidad. Los estudiantes cursantes de dicha facultad no le impidan ni embaracen el cursarla, pena de perdimiento de matricula, lo cual se le notifique a los catedráticos de Prima y Visperas de Medicina, y si tuvieren que alegar o pedir ocurran ante mi, que estoy presto a les oir y guardar la justicia que por decreto hubiere lugar [... $]^{20}$.

Cabe destacar que el rector hizo una interpretación literal de la constitución; es decir, solo debía aplicarse la constitución a quienes expresamente estuvieran señalados negros, mulatos o chinos morenos, y a nadie más. No obstante, cuando el secretario notificó la decisión a los catedráticos de Medicina, el doctor Brizuela escribió al rector para argumentar mejor por qué debía excluirse al "chino", como insistió en llamar a Santa Fe. El catedrático pedía que no se le consintiera, en cuanto resultaba insuficiente la información facilitada, agregando que él no había estado presente en la diligencia ante el secretario y que los testigos no eran confiables. Además, el catedrático alegó que la Conchinchina, de donde era originario el estudiante:

[...] está sujeto al chino y le tributa, y los naturales de ahí están mezclados con moros y sanguelles [sic], que son de los comprendidos en la constitución doscientas cuarenta y seis por aquellas palabras ni los que comúnmente se llaman chinos morenos, y tampoco dice, ni da razón cómo sabe no haber sido esclavo el dicho su padre, pues es una negativa que bien puede no haber llegado a su noticia; y el segundo testigo, que es Domingo de la Cruz, no dice la calidad de su persona, y por mi parte se ignora por el defecto de dicha citación y es singulares todo lo que depone; y en decir que Francisca Gutiérrez, madre de la parte contraria, es japona de nación y contra lo que el dicho Pablo de Santa fe tiene confesado, y se le ha oido decir extrajudicialmente ser mestiza por haberlo dicho en diversas ocasiones, como asi mismo se probará con todo lo demás que convenga y la certificación del padre Manuel Duarte. Fuera de ser instrumento dado sin citación que no debe perjudicar, más parece que obsta a la parte contraria, pues dice que su padre ni es negro, ni mulato ni indio, con que siendo chino es de los comprendidos en dicha constitución.

El doctor Brizuela argumentó que aunque lo anterior no fuera abundante bastaba con que a Santa Fe, al graduarse de bachiller, se le hubiera dado el grado bajo la condición de que no debía ser aceptado en alguna facultad mayor que necesitara de estudios previos de Filosofia, como era el caso de Medicina.

La respuesta de Santa Fe, ante el nuevo alegato del catedrático, contuvo más argumentos para probar que su caso no era el único: ...no soy comprendido en la constitución doscientas cuarenta y seis [...] respecto de ser como soy

${ }^{20}$ AGN, Universidad, vol. 69, año de 1674, expdte. 2, fols. 2v-3. 
japón blanco y este no está excluso en dicha constitución... Luego manifestó la presencia de otros médicos que no eran españoles y que, no obstante, pudieron desarrollar notables trayectorias en el ejercicio de su facultad, entre ellos el mismo Pedro Ciprés ${ }^{21}$.

Si bien Brizuela todavía insistió en que el joven era "chino prieto", que su madre era mestiza y que los médicos no españoles ...fueron en tiempo que esta universidad no se regia por los estatutos que hoy se observan..., un nuevo rector reafirmó la sentencia de su antecesor de aceptar a Santa Fe en la facultad de Medicina.

Es claro que los dos rectores a quienes correspondió dictaminar el caso de Manuel de Santa Fe mostraron una actitud tolerante y no restrictiva respecto a la aplicación de la 246, dejando a un lado un posible escándalo dentro, e incluso fuera, de la universidad. Sin embargo, nuevos problemas se presentaron en la década final del siglo XVII.

En 1691 otro estudiante filipino, Nicolás de la Peña, seguramente conocedor del caso Santa Fe, procuró voluntariamente dar información de no ser chino moreno, sino más bien ser hijo de filipinos principales, el equivalente de los caciques novohispanos ${ }^{22}$. Agustín de Cabañas, el rector de ese año, admitió el interrogatorio formulado por Peña ${ }^{23}$. Francisco Sánchez, fraile dominico y primer testigo, confirmó lo ya expuesto por Peña, y además explicó que los nativos de la provincia de Pampanga se consideraban indios naturales y vasallos libres de la Corona española; que no sabía que alguien de la familia del estudiante hubiera sido enjuiciado por el Santo Oficio, y que todos eran cristianos viejos, sin mezcla de moros o judíos. El fraile manifestó igualmente que Peña

${ }^{21}$ Ibid., f. ${ }^{\circ}$ 7: Lo otro porque, caso negado que no fuese japón sino que mi color fuese turbado y de mixtura, que niego, se experimentaron en esta ciudad los créditos del doctor Sebastián de Castro, decano de la facultad de Medicina, protomédico de esta Nueva España y que obtuvo la dignidad de sacerdote mayor, sin comparación que de médico, y también es doctor por esta universidad el doctor José Báez, que reside en la ciudad de los Ángeles. Y también se graduaron los bachilleres Domingo de Ortega y Pedro Ciprés, de que se infiere el poco y ningún fundamento con que se impugna mi pretensión...

22 ÁLVAREZ, Luis Alonso: «Los señores del barangay. La principalía indigena en las islas filipinas, 1565-1789: viejas evidencias y nuevas hipótesis», en MENEGUS, Margarita, y Rodolfo AGUIRRE (coords.): El cacicazgo en Nueva España y Filipinas, México, CESU/Plaza y Valdés, 2005, pp. 355-406.

${ }^{23}$ AGN, Universidad, vol. 42, fols. 603 y 603v. ${ }^{\circ}$ : "Información de Nicolás de la Peña y licencias para cursar en esta universidad. 1691", "Interrogatorio por donde han de ser examinados los testigos de parte para la información que ha de dar Nicolás de la Peña por las preguntas siguientes: $1^{\circ}$. Primeramente si conocen a Nicolás de la Peña natural del pueblo de Alvucai [sic] provincia de la Pampanga en las islas Filipinas. 2. ${ }^{\circ}$. Si los testigos les tocan las generales, si son de la edad que el derecho disponen, digan. $3^{\circ}$. Item. Si saben que el dicho Nicolás de la Peña es indio natural de la dicha provincia de Panpangos, si son vasallos libres de S. M. o si es de los que comúnmente llaman chinos morenos conforme a la constitución doscientas cuarenta y seis de los estatutos de esta real universidad, digan. $4 .^{\circ}$ Item. Si conforme a dicha constitución el dicho Nicolás de la Peña o sus padres o abuelos han sido o son penitenciados por el Santo Oficio de la Inquisición o si han tenido nota de infamia, porque teniéndola o siendo comprendido en las personas prohibidas por dicha constitución no pueden ser admitidos a grado de bachiller ni a la matrícula de los estudiantes de esta real universidad. $5{ }^{\circ}$ Si saben o han oido decir que el dicho Nicolás de la Peña a estudiado gramática y si la sabe para poder ser admitido a matrícula para cursar conforme a estatutos un curso en Retórica antes de entrar a oír facultad mayor... 
estudió en la universidad de Santo Tomás de Aquino, de Manila. Los otros dos testigos presentados, fray Juan de la Cueva y José Julián de Espinosa, solo reafirmaron todo lo anterior.

El rector de la universidad, a diferencia del caso de Santa Fe, decidió esta vez pedir un dictamen jurídico al abogado de turno de la universidad, el catedrático de instituto José de Miranda Villayzan. Su parecer se centra en discernir la calidad sociojurídica del alumno:

\section{[...] He reconocido la pretensión de Nicolás de la Peña y probanza con} que la instruye, $y$ hallo que por ella consta ser de los indios filipenses, natural y originario de la provincia de la Pampanga y de padres naturales también de ella, por cuya razón es vasallo libre y generalmente lo son los de las islas Filipinas por varias leyes que asi lo tienen dispuesto, especialmente la nona del título 2. ${ }^{\circ}$ del libro 6 de la Novísima Recopilación de las Indias, exceptuándose solo los naturales de las de Mindanao, que son adyacentes a las dichas islas Filipinas y sus confines, quienes (siendo de los rebelados y confederados con los enemigos de la Corona y sectarios de la ley mahometana) se declaran por esclavos en la ley 12 de dicho título I, libro 1, por el mismo caso que la constitución 246 excluye a los que se llaman chinos morenos admite a los que por tener el origen de China se llaman menos propiamente chinos, siendo indios, que son los que expresamente permite se admitan a matriculas y grados; por cuya razón parece se puede ejecutar esto con el suplicante para la matrícula de Retórica y grados y mandarlo asi el doctor rector, o lo que tuviere por más conveniente, que será siempre lo mejor. México, y enero 23 de 1691. Dr. José de Miranda Villayzan [rúbrica $]^{24}$.

Este dictamen seguía el argumento de 1674 en la defensa de Santa Fe y revalidaba la interpretación sobre que los indios de Filipinas podían ser equiparados a los de América, tanto por ser naturales de ahí como por ser vasallos libres de España. Este parangón les permitía ser admitidos en la Real Universidad. El argumento del abogado fue bien visto por el rector, quien lo ratificó y admitió al estudiante filipino en las aulas universitarias.

El ejemplo de los estudiantes de Filipinas constituyó un precedente importante para otros grupos minoritarios, pero que compartian el deseo de acceder a los estudios universitarios, incomodando a grupos menos tolerantes de españoles. Esto se evidenció en 1689, cuando se pretendió un intento general por controlar su ingreso a las escuelas, aprovechando ciertas reformas en la matriculación. El rector José Amurrio del Campo ordenó que todos los estudiantes que pretendieren matricularse en cualquiera facultad presenten fe de bautismo en debida forma ${ }^{25}$. El secretario pasó, cátedra por cátedra, a notificar esa disposición. Al final del expediente, él mismo hizo constar las fes de bautismo presentadas por los cursantes del momento, todas señalando matrimonios legitimos y el origen español de diversos estudiantes.

24 Ibid., f. ${ }^{\circ} 606$.

25 AGN, Universidad, vol. 42, fols. 422-433. 
Sin embargo, la situación se complicó bastante para la corporación universitaria, pues fue presionada desde el exterior para que fuera más excluyente en la población estudiantil después del gran tumulto de 1692 en la ciudad de México.

\section{Del tumulto de 1692 a la aplicación general de la constitución 246}

Los estudiantes de las facultades pueden ser considerados, en conjunto, como una especie de "puente" entre la universidad y la población en general. Si bien nos falta mucho por conocer esta vertiente de su historia social, hay claros indicios de que los alumnos tenian lazos, en mayor o menor medida, con otros grupos como los vagabundos, los indios de los barrios, las castas o los comerciantes callejeros. Prueba de esto fue el rechazo de un grupo de estudiantes a la clausura del "baratillo" o mercado callejero de artículos viejos y usados, ordenado por la Real Audiencia en 1690, y que les llevó a un enfrentamiento con los ministros de justicia. Estos se quejaron al rector José Amurrio del Campo, quien mandó en consecuencia que no se consentirian nuevas manifestaciones de rebeldía de los alumnos, permitiendo incluso a autoridades extrauniversitarias el apresamiento de estudiantes, no obstante el fuero universitario:

...mandó se notifique en las cátedras de Prima de todas facultades de esta Real Universidad a los estudiantes de ella a la hora de sus lecturas no se impidan ni intervengan en cualesquier diligencias que por los ministros de la Real Audiencia ejecutaren cerca de lo referido y órdenes de su majestad, ni en otra manera alguna ni con ningún pretexto, con apercibimiento que cualesquier ministros de la Real Audiencia puedan aprehender a los que contravinieren en lo contenido en este auto y traerlos ante el señor rector para que se proceda a lo que hubiere lugar en derecho; y el alguacil de esta Real Universidad tenga cuidado de recorrer el dicho baratillo o donde estaba formado, y si en el hubiere algunos estudiantes o que digan serlo los traiga ante su merced...26.

Un par de años después de los sucesos sobre el baratillo aconteció el mayor tumulto popular de que se tuviera memoria en la ciudad de México, luego de la conquista española: el del 8 de junio de $1692^{27}$. La insuficiencia de maíz causó la especulación de comerciantes y labradores en su venta al menudeo, perjudicando a la gente pobre de la capital novohispana, lo cual derivó en hechos violentos. Un inesperado motín en la tarde del domingo 8 de junio sorprendió a las autoridades, las cuales no pudieron impedir ataques graves

\footnotetext{
${ }^{26}$ AGN, Universidad, vol. 42, f. ${ }^{\circ}$ 511. 13 de febrero de 1690. "Auto del señor rector para que los estudiantes no impidan ni intervengan en cualesquiera diligencias que por los ministros de la Real Audiencia se ejecutaren".

27 ROBLES, Antonio de: Diario de sucesos notables (1665-1703), México, Porrúa, 1972, tomo II, pp. 251-270.
} 
al palacio virreinal, a las casas del Ayuntamiento de México ni el robo a los comercios de la plaza mayor ${ }^{28}$.

El 9 de junio los rebeldes fueron reprimidos con dureza, pero el ambiente de alarma, miedo y suspicacia tardó meses en desaparecer. Aunque los españoles imputaron al principio a los indios el inicio de la sedición, después fueron señalados también los negros, los mulatos y las castas ${ }^{29}$. Se endureció la vigilancia y se ordenó congregar a todos los indios de la capital en los cuatro barrios indigenas originales del siglo XVI. Sin embargo, hubo que hacer excepciones con aquellos indios estudiantes, aprendices de talleres y esposas indias de españoles que vivian con familias españolas ${ }^{30}$. El tumulto de junio reavivó el temor de un levantamiento general de los nativos contra los españoles imaginado desde el siglo XVI, recelo que fue disminuyendo en el transcurso de los meses.

Es posible que, a raíz de los hechos de 1692, en la universidad se haya tomado la decisión de aceptar solo a indios nobles, no a los comunes, siempre sospechosos de conspirar contra el orden establecido. De hecho, la nobleza indigena se deslindó de los amotinados y manifestó su respaldo al virrey para restablecer el orden ${ }^{31}$. Incluso la nobleza tlaxcalteca y de la provincia de Chalco demostraron su apoyo al virrey después del tumulto ${ }^{32}$. El rey se refirió así de los caciques de Tlaxcala: ... les aseguraréis la satisfacción con que quedo a la lealtad y amor con que han procedido en esta ocasión en continuación de la que siempre han manifestado ${ }^{33}$.

De igual forma, el virrey dispuso que las oficinas de la alhóndiga de granos, atacadas durante el incidente, ya no estuvieran en las instalaciones de la universidad, como se aprestó originalmente, temiendo una alianza entre indios y estudiantes $^{34}$. Es complicado demostrar la participación de estudiantes en el gran motín, aunque sí es válido pensar que un grupo de ellos coincidía con el desafío a la autoridad.

De todas formas, hubo consecuencias en comunidades que, como la universidad, patrocinaban el régimen social y político impuesto por los españoles. Las actividades en la universidad y los colegios se suspendieron durante algunas semanas. Esto perjudicó a estudiantes de otras regiones novohispanas que viajaban a la capital para examinarse y obtener los grados en la universidad, como sucedió a los del colegio jesuita de Oaxaca, quienes debieron esperar e incluso solicitaron al rector que les permitiera graduarse, pues de otra

28 SIGÜENZA Y GÓNGORA, Carlos de: Relaciones históricas, México, UNAM, 1972, pp. 138174.

${ }^{29}$ FEIJOO, Rosa: «El tumulto de 1692», en Historia Mexicana, México, El Colegio de México, n. ${ }^{\circ} 56$, abril-junio 1965 , p. 664.

30 Ibid., pp. 670-675.

31 SIGÜENZA Y GÓNGORA, Carlos de: Relaciones históricas, op. cit., p. 172.

32 SILVA PRADA, Natalia: «Estrategias culturales en el tumulto de 1692 en la ciudad de México: aportes para la reconstrucción de la historia de la cultura política antigua», en Historia Mexicana, México, El Colegio de México, n. ${ }^{\circ} 209$, julio-septiembre 2003, p. 49.

${ }^{33}$ AGN, Reales Cédulas, vol. 25, expdte. 10, f. ${ }^{\circ} 74 \mathrm{v},{ }^{\circ} .11$ de febrero de 1693.

${ }^{34}$ Ibid., fols. 80-80v. ${ }^{\circ}$. 
manera peligraba su regreso a casa debido a las lluvias que anegaban los caminos:

[...] Con ocasión del motin y alboroto que hubo el domingo siguiente sobre tarde en esta ciudad se han suspendido los grados de bachilleres, $y$ atento a que estamos ochenta y dos leguas de nuestra patria fuera de nuestras casas, gastando con la carestia de los bastimentos lo poco que trajimos para nuestro viaje, pretexto que ha movido a vuestra señoría a que algunos de nosotros se nos den los grados de bachiller por pobres y para conseguir el volvernos con brevedad y redimir la vejación que se nos hace, y a que están de próximas las aguas y se pondrán los rios de calidad que peligre alguno, como aconteció en otra ocasión, que volviendo de esta ciudad el bachiller don Martín de Sariñana se ahogó en el río de Quiotepec [... $]^{35}$.

Los doctores universitarios, a través del claustro de la universidad participaron también en el discurso oficial que buscó la pacificación de la ciudad de México y el retorno del orden, después de los graves sucesos del 8 de junio, por medio de un memorial que les fue solicitado por la Real Audiencia y el virrey, que condenó sobre los daños de la bebida embriagante: el pulque en los indios. La orden del Real Acuerdo fue solicitar parecer a los prelados, curas, ministros, doctrineros y demás personas graves y doctas sobre el asunto. Por ello se pidió también al claustro de la universidad. En su parte central el mandamiento indicaba que:

Con ocasión del alboroto e incendios y saqueo en que incurrieron a los ocho del corriente [...] se tuvo por conveniente providencia la suspensión de las entradas del pulque en ella a fin de excusar las embriagueces, atrevimientos, guerras y pendencias que de ordinario causan y pudieran dar cuerpo a lo referido. Y atento a que el punto de dicha suspensión y su continuación es de la gravedad que se reconoce por el interés del real haber que contiene, para que en esta razón se resuelva según el presente estado de la materia lo que más convenga al servicio de su majestad, con conferencia del Real Acuerdo se lleve a él este decreto por voto consultivo sobre la conveniencias o inconvenientes de continuar o alzar la suspensión dicha $[\ldots]^{36}$.

No obstante la desconfianza que se despertó alrededor de los indios, el hijo de un cacique se presentó a cursar en la universidad en 1692. José Montaño del Castillo pidió estudiar Retórica, argumentando que era indio natural, legítimo y cacique, ...persona de las que permite el estatuto... ${ }^{37}$. Además, el joven mostró una información sobre su legitimidad y limpieza de sangre. Un testigo fue Bartolomé Velasco, vecino español de la capital y maestro de herrería, quien manifestó que los padres eran indios puros, sin mezcla de otros grupos

\footnotetext{
35 AGN, Universidad, vol. 42, f. ${ }^{\circ}$ 698. "Petición de los estudiantes de Oaxaca sobre que prosigan los grados de bachilleres en Artes".

36 AGN, Universidad. vol. 42, fols. 673-673v, "Orden del excelentísimo señor conde de Galve para que el rector y claustro de la Real Universidad informe sobre el uso o prohibición de la bebida del pulque".

37 AGN, Universidad, vol. 42, f. ${ }^{\circ}$ 675. "1692. Información de José Montaño del Castillo para que lo admitan a cursar en la Real Universidad".
} 
sociorraciales. El rector Miguel Gonzales de Valdeosera autorizó a Montaño el ingreso en las aulas. Este caso es significativo, pues señaló una especie de requerimiento no escrito: se admitirian indios, pero no de cualquier calidad social, sino solo de la nobleza indigena.

La desigualdad social se expresó con crudeza en ese tumulto y quedó grabado en la memoria social por muchos años. De hecho, la inquietud y un ambiente de rebeldía parecieron contagiarse a los alumnos universitarios. Algunos meses después del disturbio, un grupo de estudiantes, aliados con personajes considerados "vagabundos" por el rector, mostraron una actitud retadora al reclamar al virrey la entrada libre al coliseo de comedias, ubicado muy cerca de la universidad, argumentando que esa prerrogativa la tenian los estudiantes de la universidad de Salamanca, en España, y por ello el arzobispo de México, fray Payo de Rivera, años atrás, se la había concedido ${ }^{38}$.

El virrey preguntó sobre el asunto al rector Jerónimo de Soria, quien recomendó no aceptar la solicitud considerando que los cursantes solo eran de Medicina y no representaban en realidad a todos los de la universidad; además, no le constaba la concesión del arzobispo Payo de Rivera ni los de las otras universidades, por lo que pedía esperar a que se buscasen tales testimonios. Ante esto, aunque el virrey ya habia respondido afirmativamente a los estudiantes, se retractó ${ }^{39}$. Los jóvenes pasaron de las palabras a la violencia y atacaron el edificio del colegio de Todos Santos, en donde vivía el rector Soria, e insistieron al virrey en su reivindicación. Este consultó de nuevo al rector, quien insinuó cierta relación de la actitud de los estudiantes con la de los amotinados de 1692:

\begin{abstract}
Excelentísimo señor. El rector de la Real Universidad, en obedecimiento del decreto de arriba, dice que es necesario reprimir la audacia de los estudiantes y demás personas que en nombre de tales se les juntan, como acaeció hoy, dia de la fecha, que se arrojaron al colegio más de 40 y con mucho estrépito, descompostura, alteración de voces $e$ indecentes palabras procedieron, alentados por algunos cabecillas, como vuestra excelencia reconocerá en el testimonio adjunto. Y si a la grandeza de vuestra excelencia se atreven informar con tan descomedidas razones de su rector y cabeza, se deja a su alta comprensión lo demás, que pide competente remedio para que no se causen alborotos ni se mezclen otras personas con nombre de estudiantes y sin serlo, y algunos de hábitos clericales. Vuestra excelencia, siendo servido,
\end{abstract}

\footnotetext{
38 AGN, Universidad, vol. 43, "1694. Autos sobre petición de algunos estudiantes de lugar en el coliseo de las comedias". En la foja 98 se registró así la solicitud estudiantil: Los bachilleres cursantes de la Real Universidad, llegándonos al patrocinio de vuestra alteza como mejor haya lugar, decimos que se nos ha negado la entrada en el coliseo, debiéndose como se nos debe por tres causas. La primera, que es costumbre en todas las universidades, como son Salamanca, Alcalá de Henares, etc., este fuero que sin diferencia debemos gozar. La segunda, porque corriendo como con igualdad corremos con la militar infantería no han de gozar aquellos este privilegio sin que en nosotros se halle. Y la tercera, porque años antes del presente le obtuvimos por decreto del ilustrísimo señor virrey don fray Payo de Rivera, y respecto de que puede estar, como lo está, enajenado nuestro sitio que fue, se nos dé el portal que está a la siniestra del teatro, $y$ en su defecto el sitio en que pongamos dos filas de bancas, siendo tan de las primeras que nos quedemos a la cuarta...

39 Ibid., fols. 102-103.
} 
podrá mandar que este memorial se junte con los demás de la materia, para que sobre todo se haga y el informe y en los demás lo que vuestra excelencia fuere muy servido ordenar, que será, como siempre, lo más acertado y conveniente [...] Colegio de Santos, 30 de julio de 1694. Soria [rúbrica] ${ }^{40}$.

El fiscal de la Real Audiencia de México, Juan de Escalante y Mendoza, apoyó la postura del rector y declaró que a él le constaba que en Salamanca los estudiantes no tenían acceso gratis al coliseo de comedias. Además, el fiscal añadió que el no cobrar a los alumnos afectaría a los ingresos del hospital real de los indios, que se sostenía del coliseo, sin contar con que ...con el nombre de estudiantes se agregara el concurso de otros vagabundos que quisieran gozar del privilegio sin ser fácil la distinción y se llenara el coliseo de suerte que no quedase lugar para otros algunos... ${ }^{41}$. Contando con el respaldo del virrey y la Real Audiencia, el rector Soria decretó que, para impedir que los estudiantes se juntaran con los vagabundos, les prohibía asistir al coliseo, solos o acompañados, y pidió al encargado de este informar a la universidad qué cursantes entraban a las comedias y con qué compañias para expulsarlos de la universidad.

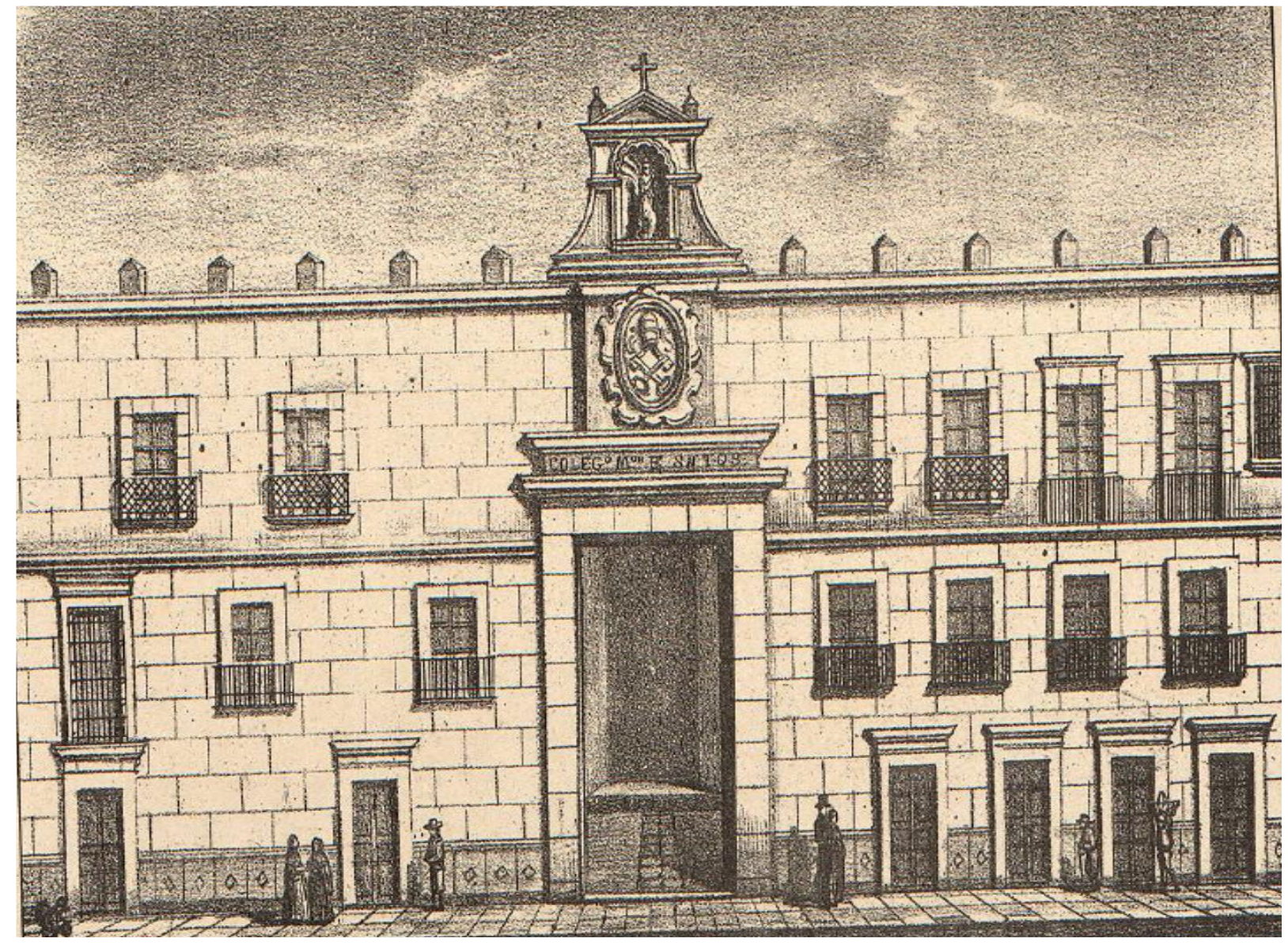

Imagen: Fachada del colegio de Todos Santos, atacado por estudiantes inconformes. Tomada de: RIVERA CAMBAS, Manuel: México pintoresco, artístico y monumental, en:

https://cd.dgb.uanl.mx/handle/201504211/12953 bajo licencia Creative Commons.

40 AGN, Universidad, vol. 43, fols. 103-103v. ${ }^{\circ}$.

41 Ibid., fols. $103 \mathrm{v}-104$. 
Las autoridades decidieron no castigar a los estudiantes que agredieron el colegio de Todos Santos y dejaron el asunto a la decisión del rector universitario. Con todo, tales hechos sembraron más recelos en todas ellas: a los rectores, porque ese tipo de eventos rebasaban la capacidad de acción de una corporación académica; y al virrey, porque la evocación del tumulto de 1692 era inevitable. Igualmente, hubo preocupación en la Iglesia, pues se había acusado también a estudiantes vestidos con hábitos clericales ${ }^{42}$.

Los problemas de los estudiantes en el coliseo de comedias no terminaron. En 1708 el mayordomo del hospital de los indios y cobrador del coliseo acusaron al cursante de Leyes, Bernardo Gómez, de que, agavillado con otros, había causado un escándalo en el coliseo. Cuando el secretario le reprochó a Gómez su conducta, este declaró que había ido solo y que el cobrador lo había provocado. El rector amonestó al estudiante y le prohibió acudir nuevamente a las comedias.

Como resultado, comenzó una mayor vigilancia en la aceptación de estudiantes a las facultades, pero ya no solo de indios, mulatos o asiáticos sino ahora también de los estudiantes españoles de quienes habia alguna duda ${ }^{43}$. Por ello, se comenzó a pedir a todos, indistintamente, la fe de bautismo para demostrar que no eran de los prohibidos por estatuto. En cuanto a los indios, se consolidó la tendencia a presentarse preferentemente jóvenes descendientes de caciques y principales, a pesar de que la constitución 246 sólo exigía la calidad "indios" sin ninguna adicional. Lo mismo sucedió con los "indios" fili$\operatorname{pinos}^{44}$.

A pesar de estas medidas, muchachos no españoles de baja procedencia social lograron colarse en las aulas sin abandonar sus actividades "callejeras" ni sus muestras de rebeldia contra el orden social dominante. El 27 de marzo de 1696 otro grupo de estudiantes y vagabundos arrebató comida a vendedoras de una plaza pública del centro de la capital. No conformes con esto, quemaron la picota ante la mirada atónita de la Audiencia, tal y como había sucedido en el tumulto de $1692^{45}$.

La provocación fue respondida por el virrey interino, por entonces el obispo de Michoacán Juan de Ortega y Montañés, con un proyecto para "limpiar" a la población estudiantil. El 6 de abril envió una consulta al claustro de la universidad, que en el fondo era una orden, pues mandó al secretario de la universidad no matricular, probar curso ni dar grado a cualquier estudiante

42 AGN, Universidad, vol. 45, fols. 51-52.

43 AGN, Universidad 43, f. ${ }^{\circ}$ 75. 11 de marzo de 1693: Francisco Luis de Castri, cursante de Leyes, presenta información de su legitimidad; y f. ${ }^{\circ}$ 497, año de 1698, Victoriano Antonio, hijo de la Iglesia, aunque bautizado como español, y adoptado por Juan Francisco Neri, receptor de la Audiencia.

44 AGN, Universidad 43, fols. 160-162. Año de 1695: "Información hecha por el bachiller Ignacio de Noruega Manesay". Su padre fue el capitán y sargento mayor Juan de Noriega Manesay y María Danlac, principala del pueblo de Bacolor.

45 AGN, Universidad 43, fols. 326-328v. ${ }^{\circ}$. 1697. Proceso de un estudiante. Juez: el rector Manuel de Escalante y Mendoza. 
que vistiera "profanamente" 46 . Pero no solo esto, sino que el virrey obispo, excediendo lo estipulado en la constitución 246, decretó que:

[...] totalmente se excluyan de las matriculas los que no fueren españoles, en consideración de ser los que turban la paz y sin respeto alguno de la justicia se unen y adjuntan no solo a impedir que la justicia seglar practique su oficio, prendiendo los malhechores, sino que, creciendo sus atrevimientos han practicado quitar los presos a los ministros tan petulante $y$ soberbiamente que han pasado a perder el respecto a los señores alcaldes de la Corte, como sucedió el día 27 de marzo $[\ldots]^{47}$.

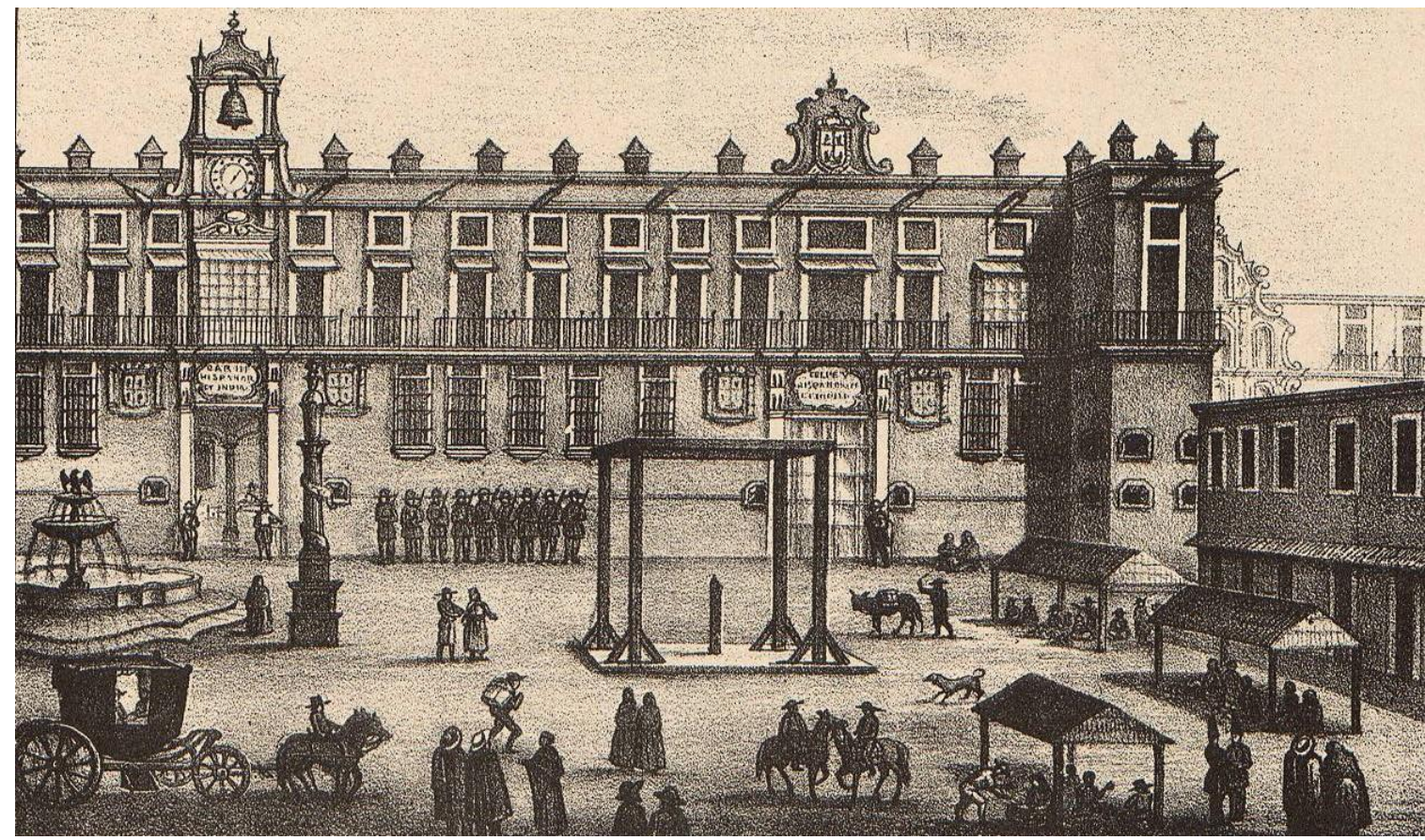

Imagen: Plaza mayor de México. Al centro se observa la picota, como la incendiada por los estudiantes universitarios en 1696. Tomada, bajo licencia Creative Commons, de: RIVERA CAMBAS, Manuel: México pintoresco, artístico y monumental, en: [<https://cd.dgb.uanl.mx/handle/201504211/12953].

46 AGN, Universidad, vol. 43, f. ${ }^{\circ}$ 229. "Auto del señor rector para que se guarde y cumpla el edicto para la observancia de las constituciones sobre los trajes de los cursantes y lo demás que contiene el dicho edicto". Agregaba que ...se les prevenga procedan, vivan y obren contenidos y como quienes se crían para servir a ambas majestades en lo espiritual y politico... Los estudiantes seglares, o laicos, debían usar capa o manteo oscuros, mientras que los clérigos debian usar su sotana solamente.

47 Ibid. La parte final de la "consulta" del virrey Ortega especificaba lo referente al vestido de los estudiantes: Enseguida, la petición al claustro: ... En lo primero que mira a la honestidad y decencia con que los estudiantes deben cursar en sus trajes y guedejas se ponga el debido cuidado para que tenga el exceso total remedio de manera que su honesto vestir, ora sea de largo o corto y el no usar de pelo, sea un ejemplar conocimiento para todos de ser estudiante el que asi anda; y como el ejemplo de los mayores es quien más mueve para la imitación de los inferiores, se mande reformar en los graduados lo que excedieren en los trajes y pelo... Y totalmente se excluyan de las matrículas los que no fueren españoles... En palacio, a treinta y uno de marzo de mil seiscientos noventa y seis. 
El claustro universitario, intimidado, admitió la orden sin ninguna inconformidad formal por el exceso de interpretación de la constitución 246, que dejaba a los indios y mestizos fuera de los estudios universitarios. La resolución del claustro universitario consistió en publicar y hacer cumplir las constituciones 236, sobre el vestido de los estudiantes, y la 246:

...y no se admita a matrícula, curso ni confiera grado alguno el que no fuere español, prohibiendo los negros, mulatos, chinos morenos; y como está mandado por el claustro pleno, el infrascrito secretario no reciba matricula a ninguno que anduviere profanamente vestido y con guedejas ni se le pruebe curso ni confiera grado alguno, y totalmente sean excluidos de matrícula los que no fueren españoles, en consideración de ser los que turban la paz y unión de las universidades... ${ }^{48}$.

Afortunadamente para los jóvenes, la universidad no llegó a proponer ante el rey la reforma de la 246 para formalizar lo dispuesto por el edicto del obispo virrey.

\section{El desarrollo posterior del estatuto de exclusión en las escuelas}

Después del edicto restrictivo de 1696 hubo un compás de espera en la universidad. La orden dada al secretario de la universidad fue exigir a todos los alumnos que se quisieran matricular la presentación de fe de bautismo de ser españoles, tal y como expresaba el edicto ${ }^{49}$. Debido al tumulto de 1692 y al virrey Ortega y Montañés, el problema del origen social de los estudiantes se intentó reducir al concepto de ser o no español. En los años inmediatos posteriores los rectores intentaron promover ese edicto. En los trámites de grados mayores se solicitó a los estudiantes presentar información de legitimidad y limpieza de sangre, sustituyendo a la más simple de vida y costumbres. En adelante, y hasta el siglo XIX, los expedientes de grados mayores se integraron por esas informaciones, varias de las cuales son extensas, pues incluyen considerables probanzas sobre linajes de origen peninsular, libros genealógicos y escudos de armas ${ }^{50}$.

A pesar de estas demostraciones de ennoblecimiento de la elite académica, al iniciar el siglo XVIII, a solo una década del motín, estudiantes no españoles comenzaron nuevamente a presentarse en la universidad. Los hijos de caciques indigenas insistieron en matricularse y en graduarse, buscando los curatos de sus regiones de origen. En 1704, un estudiante indio, Pascual del Espíritu Santo, solicitó al rector poder matricularse ...atento a ser noble de que ofrezco información, se ha de servir vuestra señoría admitirme a matrícula

\footnotetext{
48 Ibid.

49 AGN, Universidad, vol. 43, f. ${ }^{\circ}$ 222, 3 de noviembre de 1696: José de Ordaz, cursante de la facultad de Artes en la ciudad de Oaxaca, ante vuestra merced parezco y digo que cursé tres cursos, como consta por la certificación que presento; y porque pretendo echar matricula en la facultad de Leyes y por vuestra merced está mandado por edicto que todos los que fueren cursantes presenten fe de bautismo o den información de que son españoles, y porque no me hallo al presente con dicha fe de bautismo, estoy pronto a dar información de que soy hijo legitimo de don Cristóbal de Ordaz y doña María de Cabrera, mis padres, vecinos de dicha ciudad, y de cómo son españoles, cristianos viejos, limpios de toda mala raza...

50 AGUIRRE SALVADOR, Rodolfo: El mérito y la estrategia..., op. cit., pp. 85-160.
} 
en estas escuelas, por estar arreglado a estatuto, leyes y derecho que me favorece y según ejemplares, para que pueda estudiar hasta poder ordenarme... ${ }^{51}$. Por su parte, mestizos y mulatos intentaron pasar por españoles para ser aceptados, con desiguales resultados. Nuevas condiciones favorecian su ingreso: la reivindicación de una cédula de 1588 que permitía la ordenación a los mestizos ${ }^{52}$, la fundación de becas para caciques en los seminarios tridentinos en 1691 y la nueva cédula de 1697 que ordenó a las autoridades de Nueva España permitir a la nobleza indigena acceder a todos los cargos públicos fueron tres momentos decisivos que repercutieron directamente en las aspiraciones de mestizos e indios por alcanzar estudios mayores ${ }^{53}$. En 1714 , Sebastián Álvarez, originario del real minero de Taxco, presentó una fe de bautismo que registraba su calidad de castizo. El secretario universitario le negó la inscripción por no ser español puro; en respuesta, el estudiante escribió una carta al rector, en cuya parte central declaró que:

Habiéndome pedido el secretario de la Real Universidad, y mostrándole mi fe de bautismo [...], no quiso matricularme para el curso de Retórica por decir que de ella consta el ser mis padres castizos y prohibir una de las constituciones de dicha Real Universidad el que se matriculen sujetos de esta calidad; y aunque sea asi se ha de servir vuestra señoria de mandar que dicho secretario me eche dicha matricula y demás necesarias declarando en caso necesario no haber constitución que lo prohiba, y de haberla, estar derogada en el caso presente, que asi procede y debe hacerse porque encargando su majestad por ley real de Indias a los señores arzobispos y obispos que, no obstante cualesquiera constituciones, provean que las mestizas sean admitidas en los monasterios de monjas y a las profesiones, y a los mestizos los promuevan al sacro orden sacerdotal en sus distritos, precediendo información sobre vida y costumbres y de ser hijos legitimos concurriendo en ellos la suficiencia, poniéndola por prerrequisito como indispensable para dicho orden, claramente ordena su majestad se admitan los de esta calidad a cursar en su Real Universidad donde se instruyan $y$ adquieran la suficiencia necesaria [... $]^{54}$.

Es notable la defensa que hizo Álvarez de su origen castizo. Otros estudiantes, calificados en su fe de bautismo como mulatos, buscaron también el acceso a la universidad, alegando errores de escribano. Lo notable es que la universidad, antes de rechazarlo, prefirió emprender su propia averiguación, como en el caso de Francisco Sánchez. En este caso, su padre, Leandro Sánchez argumentó un supuesto error en la fe de bautismo:

...parece que se le pone obstáculo de mulato por haberse errado la partida cuando se bautizó, por lo cual me conviene probar y averiguar que el dicho Francisco Sánchez, mi hijo, es castizo por ser yo español, y Maria de los Ángeles mi mujer y su madre es mestiza, descendiente

51 AGN, Universidad, vol. 44, f. ${ }^{\circ} 453$.

52 Recopilación de leyes..., op. cit., f. ${ }^{\circ} 32 \mathrm{r}$.

53 AGN, Reales Cédulas originales, vol. 27, expdte. 11, de 26 de marzo de 1697.

54 AGN, Universidad, vol. 46, fols. 99-99v, 23 de abril de 1714. 
[de] caciques, y que por ninguna linea tenemos sangre de negros, mulatos ni otra casta semejante; demás de ello, el que soy yo y la dicha mi mujer y demás de nuestro linaje cristianos viejos, limpios [de] otro cualquier obstáculo, y que como tales hemos sido habidos y tenidos $y$ comúnmente reputados. Por todo lo cual, a vuestra merced pido y suplico se sirva de mandar se me reciba información del que el dicho mi hijo es tal castizo... 55 .

El rector Rodrigo Flores de Valdés ordenó se le recibiera información. El primer testigo fue Andrés de Porras, sastre, quien declaró que Leandro era español, oficial de platero, y la madre, María de los Santos, castiza: ...hija legitima de don Gregorio Manssio [sic], cacique principal intérprete que fue en esta Corte, descendiente del monarca Moctezuma... habidos, tenidos y reputados por tales nobles, cristianos viejos, limpios de toda mala raza de moros, moriscos, indios plebeyos, catecúmenos ni penitenciados ${ }^{56}$. Los otros testigos simplemente ratificaron todo lo anterior, y fueron: Juan de la Cueva Ruano, maestro del arte de escribir; el presbítero y bachiller Francisco Carabantes, sacristán mayor en Santa Catarina Mártir; y Antonio Bravo, locero.

Luego de las declaraciones de los testigos, el rector envió la diligencia al doctor Agustín Franco, catedrático de Clementinas, pidiendo un dictamen jurídico. La respuesta del jurista ejemplifica la postura que predominó en adelante y se constituyó en una especie de principio no escrito de tolerancia:

Señor rector. He visto en obedecimiento del mandato de vuestra señoría la información dada por Leandro Sánchez y la hallo suficiente para el efecto que pretende, respecto de haber probado bien y cumplidamente tener la mayor parte de español, y por parte de padre su hijo Francisco Sánchez; y asi debe regularse como tal por traer según derecho, la mayor parte asi el todo, y más siendo la mas noble, Y cuando fuera castizo o mestizo, no tenía prohibición, por no hallarse estos expresamente prohibidos en la constitución doscientas cuarenta y seis, como debian hallarse para poder ser excluidos, por ser los estatutos de naturaleza tan estricta que no se pueden ampliar a casos no expresos, además que en la misma constitución se dice que deben ser admitidos los indios, con que no constituyendo la mezcla en derecho nueva especie, si no es donde se expresa, siendo españoles e indios capaces de ser admitidos lo debe ser el suplicante por ambos extremos, y asi lo juzgo punto de justicia y no de gracia [... $]^{57}$.

¿Por qué los juristas de la universidad se apegaron en adelante a este tipo de dictámenes, que ignoraron el rigor del edicto de 1696 ? ¿Estimaron que este solo había respondido a los efectos del tumulto, y que una vez superados estos ya no hacía falta tanta dureza? Por ahora es dificil aportar una explicación categórica, pero lo cierto fue que la tendencia durante el resto del período colonial consistió en una mayor tolerancia con respecto a los origenes sociales

55 AGN, Universidad, vol. 44, f. 32.

56 AGN, Universidad, vol. 44, f. 32.

57 Ibid., fols. 35v-36. 
de los estudiantes. Así parece reflejarlo la cada vez mayor presencia de bachilleres con "defecto de nacimiento", como los de padres desconocidos o no casados legítimamente. La única exigencia a ellos fue que pudieran demostrar su origen español, para salvar así la reputación de la universidad. Esta salida permitió que en el resto del siglo XVIII muchos estudiantes con tales orígenes fueran admitidos ${ }^{58}$. Tres ejemplos, de los muchos que pueden citarse para dicha centuria son: José Francisco de Sámano, abandonado al nacer en la casa de Juan de Sámano, dueño de mayorazgo, pidió que se le recibieran informaciones de ser español, para poder estudiar en la universidad; Rafael Gutiérrez, vecino de México y estudiante de Retórica, tenía registrado en su fe de bautismo ser hijo de la Iglesia. Un testigo declaró que el padre, Jerónimo Gutiérrez, era oficial de pluma. El rector Ojendi le autorizó el ingreso. Y Juan José Venancio, bautizado como hijo de la Iglesia. Su padre, José del Castillo, soltero, pidió al rector le dejase matricularse, puesto que estaba inclinado a los estudios y al sacerdocio, obligándose a que, en término de tres años, obtendria bula de dispensa del papa.

\section{Algunas reflexiones finales}

Según lo expuesto en las páginas anteriores, es posible afirmar que en el siglo XVII la población estudiantil de la Real Universidad de México se volvió más heterogénea desde el punto de vista social. Aunque en su fundación, en el siglo XVI, esta corporación fue proyectada como un espacio de formación de letrados de los descendientes de conquistadores y colonizadores españoles, en la práctica la demanda de estudios mayores y grados universitarios se hizo extensiva a grupos sociales emergentes en el siglo XVII que deseaban también la promoción social y la distinción, sin importar su origen no hispánico. Con ello, la Real Universidad comenzó a alejarse de aquella corporación de españoles que su elite pretendía, ante la monarquía y la sociedad.

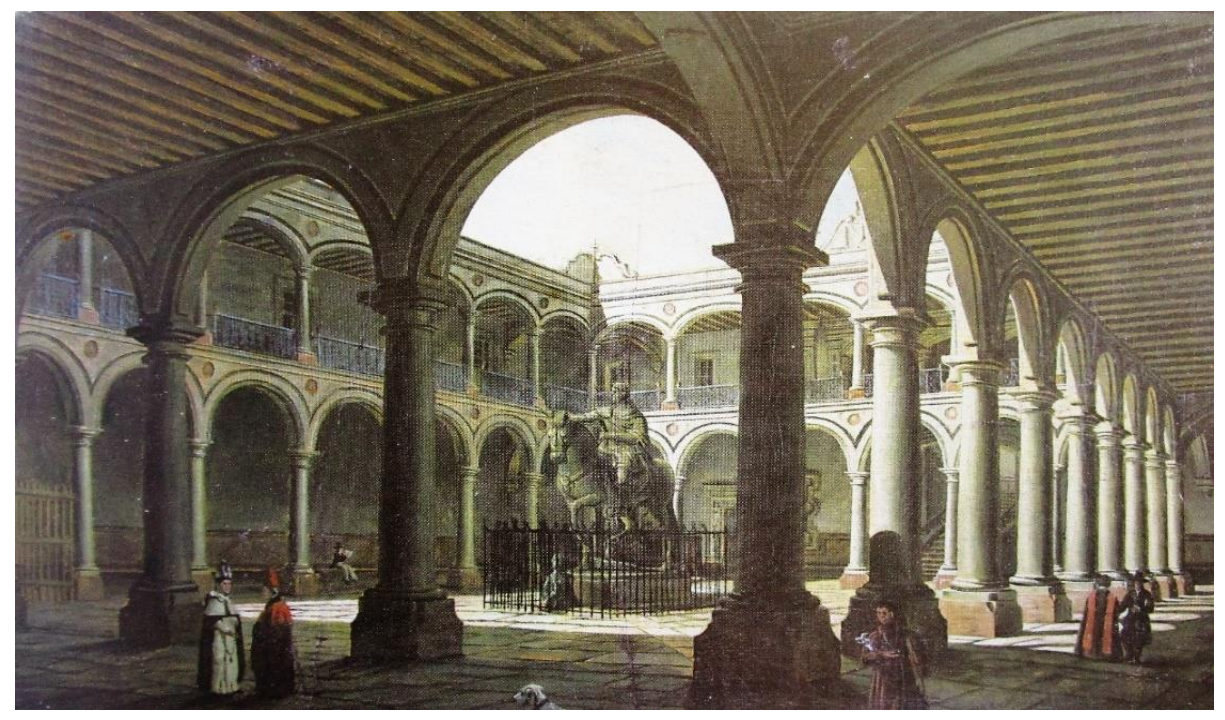

Imagen: Patio interior de universidad a principios del siglo XIX, un lugar de convivencia cotidiana de los universitarios. Pintura de Pedro Gualdi. (Imagen de dominio público: Wikimedia Commons).

58 AGN, Universidad, vol. 45, fols. 92- 92v, 1708; vol. 46, fols. 107-108v, 1713 y vol. 46, fols. 631-632, 1717, respectivamente. Puede verse también el vol. 81, con decenas de casos sobre estudiantes con problemas para demostrar su limpieza. 
En ese cambio del régimen social universitario de Nueva España fue crucial la actitud de diversos doctores, catedráticos y rectores que apoyaron una mayor tolerancia social, aun en contra de otros grupos en el seno de la universidad menos tolerantes y que exigían la exclusión de mulatos, indios o asiáticos. Los primeros escudriñaron procedimientos y discursos que conciliaran lo estipulado por la constitución 246 con las nuevas realidades sociales que se manifestaban en los estudiantes. Es de llamar la atención que no hubiera intentos por derogar tal norma, a pesar de que a medida que avanzó el tiempo se volvió anacrónica y una muestra de intolerancia social.

Si bien la Real Universidad de México siguió teniendo a los estudiantes españoles como una mayoria, es muy posible que, al ser aceptados los indios y los castizos, se haya abierto la puerta a mestizos y mulatos que de una u otra forma consiguieron documentos probatorios, principalmente fes de bautismo, para hacerse pasar como los estudiantes sí permitidos.

Una investigación futura profundizaría más en el conocimiento de grupos de estudiantes no españoles favorecidos por la apertura social de los estudios mayores en Nueva España, así como en las repercusiones de este proceso en la movilidad social de grupos bajos y medios de la sociedad.

\section{Bibliografia}

AGUIRRE SALVADOR, Rodolfo: El mérito y la estrategia. Clérigos, médicos y juristas en Nueva España, México, CESU/Plaza y Valdés, 2003.

- «Mismas aulas, diferentes destinos. Los estudios universitarios como factor de ascenso en las carreras públicas», en: Historia Mexicana, México, El Colegio de México, n. ${ }^{\circ}$ 260, abril-junio de 2016, pp. 1709-1749.

ALBERRO, Solange: Inquisición y Sociedad en México. 1571-1700, México, Fondo de Cultura Económica, 1988.

ÁLVAREZ, Luis Alonso: «Los señores del barangay. La principalía indígena en las islas filipinas, 1565-1789: viejas evidencias y nuevas hipótesis», en $\mathrm{ME}-$ NEGUS, Margarita Menegus, y Rodolfo AGUIRRE (coords.): El cacicazgo en Nueva España y Filipinas, México, CESU/Plaza y Valdés, 2005, pp. 355-406.

FEIJOO, Rosa: «El tumulto de 1692», en Historia Mexicana, México, El Colegio de México, n. ${ }^{\circ}$ 56, abril-junio 1965, pp. 656-679.

GIBSON, Charles: Los aztecas bajo el dominio español. 1521-1821. México, Siglo XXI, 1989.

GONZALBO, Pilar: "¿Qué hacemos con Pedro Ciprés? Aproximaciones a una metodología de la vida cotidiana", en Historia Mexicana, México, El Colegio de México, n. ${ }^{\circ}$ 68, 2018, pp. 471-507.

GONZÁLEZ GONZÁLEZ, Enrique, y Víctor GUTIÉRREZ RODRÍGUEZ (eds.): Juan de Palafox y Mendoza. Constituciones para la Real Universidad de México (1645), México, Universidad Nacional Autónoma de México, 2014. 
LIRA, Andrés y MURO, Luis: "El siglo de la integración", en Historia General de México. Versión 2000, México, El Colegio de México, 2000, pp. 307-362.

MARTÍNEZ, Pilar, Elisa Itzel GARCÍA, y Marcela Rocío GARCÍA: III concilio y Directorio, libro 1 , título IV «De la vida, fama y costumbres de los que se han de ordenar", parágrafo III: "Los indios y los mestizos no sean admitidos a los sagrados órdenes sino con la mayor y más cuidadosa elección", en: MARTÍNEZ, Pilar (coord.): Concilios provinciales mexicanos. Época colonial, México, Instituto de Investigaciones Históricas, 2004. Disco compacto.

MENEGUS, Margarita: "Dos proyectos de educación superior en la Nueva España en el siglo XVI. La exclusión de los indigenas de la Universidad", en VV. AA.: Historia de la Universidad colonial (avances de investigación), México, CESU-UNAM, 1987, pp. 83-89.

PALAFOX Y MENDOZA, Juan de: Manual de estados y profesiones. De la naturaleza del indio, México, UNAM/Miguel Ángel Porrúa, 1986.

Recopilación de leyes de los reynos de las Indias. 1681, México, Escuela Libre de Derecho/Miguel Ángel Porrúa, 1987. Edición facsimilar.

ROBLES, Antonio de: Diario de sucesos notables (1665-1703), México, Porrúa, 1972, 2 tomos.

SIGÜENZA Y GÓNGORA, Carlos de: Relaciones históricas, México, UNAM, 1972.

SILVA PRADA, Natalia: «Estrategias culturales en el tumulto de 1692 en la ciudad de México: aportes para la reconstrucción de la historia de la cultura política antigua», en Historia Mexicana, México, El Colegio de México, n. ${ }^{\circ} 209$, julio-septiembre 2003, pp. 5-63.

\section{Fuentes archivisticas}

-AGN, Reales Cédulas originales, vol. 25.

-AGN, Reales Cédulas originales, vol. 27.

-AGN, Universidad, vol. 129, relaciones de méritos de graduados.

-AGN, Universidad, vol. 263, grados mayores de Cánones, 1662-1699.

-AGN, Universidad, vol. 277, grados mayores de Leyes, 1570-1689.

-AGN, Universidad, vol. 284, grados mayores de medicina, 1567-1647.

-AGN, Universidad, vol. 42, libro de gobierno.

-AGN, Universidad, vol. 43, libro de gobierno.

-AGN, Universidad, vol. 44, libro de gobierno.

-AGN, Universidad, vol. 45, libro de gobierno.

-AGN, Universidad, vol. 46, libro de gobierno.

-AGN, Universidad, vol. 69, libro de gobierno.

-AGN, Universidad, vol. 81, informaciones de limpieza de sangre. 